\title{
An uncommon cause of haemoptysis in a 69-year-old women
}

\section{Alaa M Ali, Aram Barbaryan, Suartcha Prueksaritanond, Aibek E Mirrakhimov}

Saint Joseph Hospital, Chicago, Illinois, USA

\section{Correspondence to} Dr Aibek E Mirrakhimov, amirrakhimov1@gmail.com
To cite: Ali AM, Barbaryan A,

Prueksaritanond $\mathrm{S}$, et al. BMJ Case Rep Published online: [please include Day Month Year] doi:10.1136/ bcr-2013-008756

\section{DESCRIPTION}

A 69-year-old Caucasian women presented to the clinic with haemoptysis. Review of the systems was otherwise negative. Her medical history was significant for uterine carcinosarcoma, which was diagnosed 3 years ago and treated with total hysterectomy, bilateral salpingo-oophorectomy, pelvic and para-aortic lymph node dissection with chemotherapy and radiation therapy.

Physical examination was non-contributory. Chest X-ray (CXR) revealed right upper lobe masslike density concerning for a malignancy (figure 1).

Subsequent CT of the chest was performed, which showed bilateral lung masses (figure 2).

CT-guided biopsy of the lung mass was performed and pathology examination showed poorly differentiated carcinoma, consistent with metastatic uterine carcinosarcoma, with marked nuclear polymorphism, abundant foamy cytoplasm and areas of surrounding necrosis (figure 3). Compared with the patient's original uterine carcinosarcoma the morphological findings were similar.

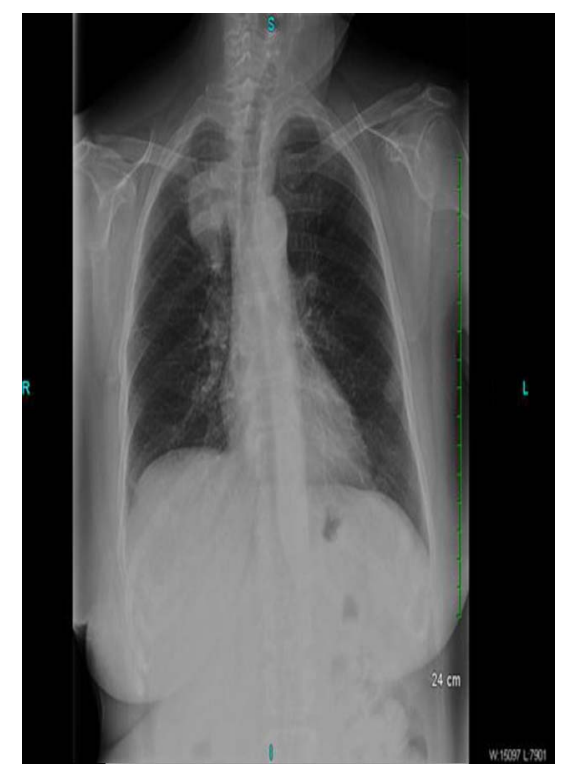

Figure 1 Chest X-ray showing right upper lobe mass.

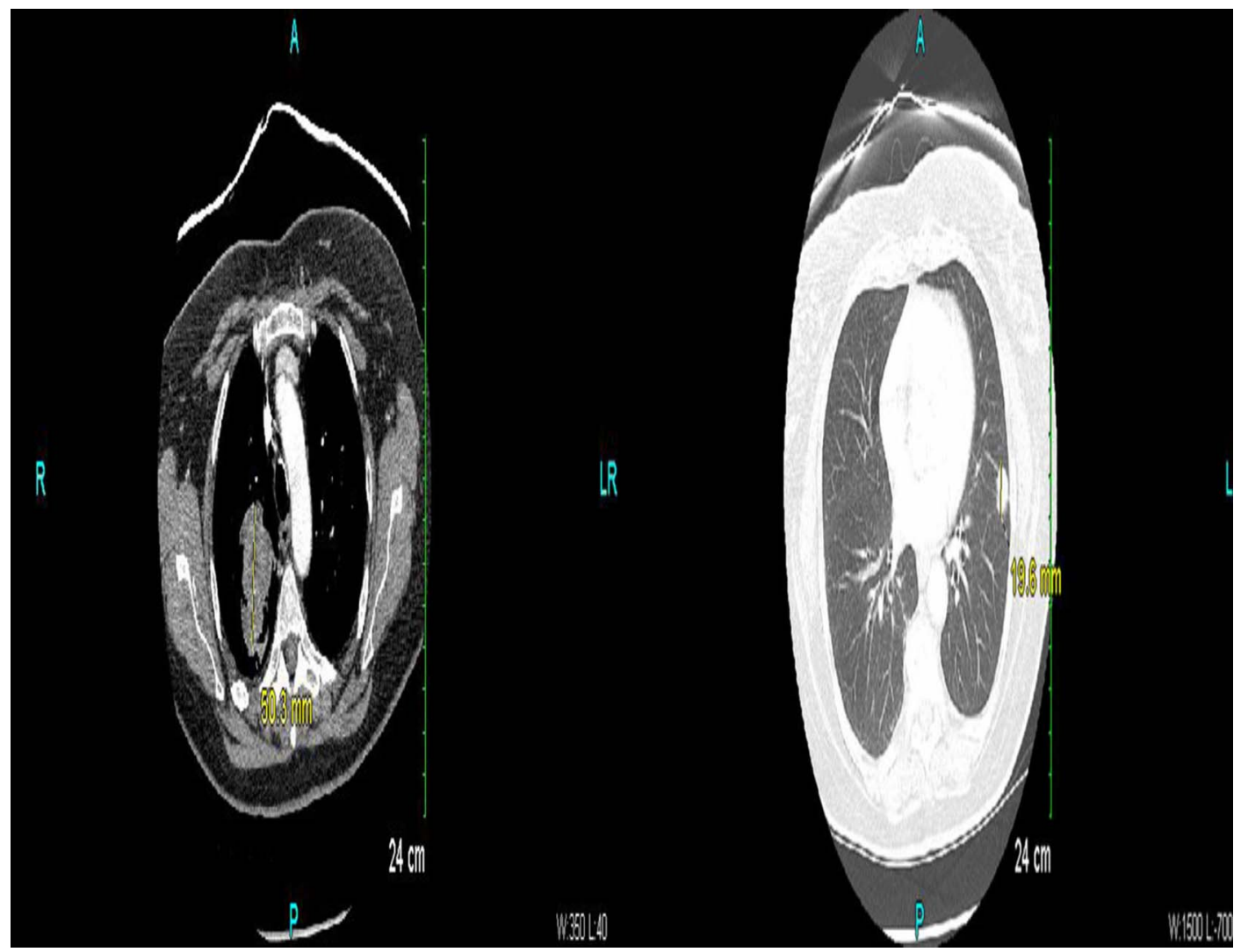

Figure 2 CT of the chest showing bilateral lung masses. 


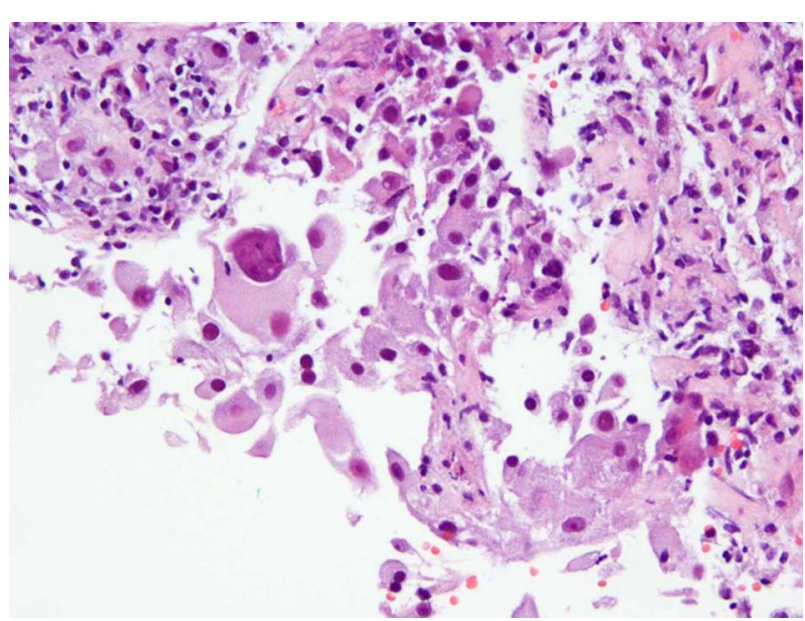

Figure 3 Lung metastatic site of uterine carcinosarcoma shows the poorly differentiated carcinomatous (epithelial) component.

The patient was started on ifosfamide and cisplatin, with radiological resolution after five cycles of chemotherapy. One year later, the patient denied any complaint and chest radiograph did not show any evidence of metastatic tumour.

Uterine carcinosarcomas include a heterogeneous group of rare tumours that usually have an aggressive behaviour and pertain a poor prognosis. Numbers of recent studies have examined the influence of radiation, chemotherapy and combinations of chemotherapy and radiation for the incidence of uterine carcinosarcoma. ${ }^{1}$ The management consists of surgical resection and chemotherapy with isofosfamide and/or cisplatin. However, some clinical studies failed to show any incremental benefit combining these medications. $^{2}$ On the other hand, a separate phase III trial showed that compared with ifosfamide alone, ifosfamide plus cisplatin resulted in a higher response rate and a significant improvement in progression-free survival. ${ }^{3}$

\section{Learning points}

- Uterine carcinosarcomas (previously called malignant mixed Müllerian tumours) are dedifferentiated (metaplastic) carcinomas comprised of carcinomatous and sarcomatous elements arising from a single malignant clone.

- While both components must be present in the uterine specimen to make this diagnosis, metastatic sites are generally composed of the carcinomatous (epithelial) portion.

- The management of the primary tumour consists of surgical resection, radiotherapy and chemotherapy with isofosfamide and/or cisplatin. Chemotherapy is the main treatment for metastatic disease.

\section{Competing interests None.}

Patient consent Obtained.

Provenance and peer review Not commissioned; externally peer reviewed.

\section{REFERENCES}

1 Gurumurthy M, Somoye G, Cairns M, et al. An update on the management of uterine carcinosarcoma. Obstet Gynecol Surv 2011;66:710-16.

2 Sutton G, Brunetto VL, Kilgore L, et al. A phase III trial of ifosfamide with or without cisplatin in carcinosarcoma of the uterus: a Gynecologic Oncology Group Study. Gynecol Oncol 2000;79:147-53.

3 Homesley HD, Filiaci V, Markman M, et al. Gynecologic Oncology Group. phase III trial of ifosfamide with or without paclitaxel in advanced uterine carcinosarcoma: a gynecologic oncology group study. J Clin Oncol 2007;25:526-31.

Copyright 2013 BMJ Publishing Group. All rights reserved. For permission to reuse any of this content visit http://group.bmj.com/group/rights-licensing/permissions.

BMJ Case Report Fellows may re-use this article for personal use and teaching without any further permission.

Become a Fellow of BMJ Case Reports today and you can:

- Submit as many cases as you like

- Enjoy fast sympathetic peer review and rapid publication of accepted articles

- Access all the published articles

- Re-use any of the published material for personal use and teaching without further permission

For information on Institutional Fellowships contact consortiasales@bmjgroup.com

Visit casereports.bmj.com for more articles like this and to become a Fellow 